CARDIOVASCULAR MEDICINE

\title{
Comparison of clinical and morphological characteristics of Staphylococcus aureus endocarditis with endocarditis caused by other pathogens
}

\author{
G Nadji, J P Rémadi, F Coviaux, A Ali Mirode, A Brahim, M Enriquez-Sarano, C Tribouilloy
}

Heart 2005;91:932-937. doi: 10.1136/hrt.2004.042648

See end of article for authors' affiliations

\section{Correspondence to:} Correspondence to:
Professor Christophe Tribouilloy, Département de Cardiologie, Hôpital Sud, Avenue René Laënnec, 80054 Amiens Cédex 1, France; tribovilloy.christophe@ chu-amiens.fr

Accepted

22 September 2004
Objectives: To analyse clinical, echocardiographic, and prognostic characteristics of Staphylococcus aureus infective endocarditis (IE) compared with endocarditis caused by other pathogens.

Design: Cohort study.

Methods: 194 consecutive patients with definite IE according to the Duke criteria prospectively examined by transthoracic and transoesophageal echocardiography were enrolled. Patients without identified microorganisms were excluded. The $S$ aureus IE group $(n=61)$ was compared with the group with IE caused by other pathogens ( $\mathrm{n}=133$ ).

Results: Compared with IE caused by other pathogens, $S$ aureus IE was characterised by severe comorbidity, a shorter duration of symptoms before diagnosis, and a higher prevalence of right sided IE, cutaneous portal of entry, and history of renal failure. Severe sepsis, major neurological events, and multiple organ failure were more frequent during the acute phase in S aureus IE. In-hospital mortality (34\% $v 10 \%, p<0.001$ ) was higher in patients with $S$ aureus IE and the 36 month actuarial survival rate was lower in $S$ aureus IE than in IE caused by other pathogens (47\% v68\%, $\mathrm{p}=0.002)$. Multivariate analyses identified $S$ aureus infection as a predictive factor for in-hospital mortality and for overall mortality.

Conclusions: $S$ aureus IE compared with IE caused by other pathogens occurs in a more debilitated clinical setting and is characterised by a higher prevalence of severe sepsis, major neurological events, and multiple organ failure leading to higher mortality.
S taphylococcus aureus and streptococci are the main microorganisms responsible for infective endocarditis (IE). ${ }^{1}{ }^{2} S$ aureus IE is a malignant disease, with a constantly increasing frequency estimated between 17-40\% of cases in recent series. ${ }^{1-8}$ Few studies have been specifically devoted to $S$ aureus IE, ${ }^{9-14}$ have not compared $S$ aureus IE with IE caused by other microorganisms, and have not systematically used transoesophageal echocardiography (TOE). The objective of this single centre study was to analyse the clinical, echocardiographic, and prognostic characteristics of $S$ aureus IE and to compare them with the characteristics of IE caused by other pathogens.

\section{METHODS}

\section{Patients}

Between January 1990 and December 2000, 243 consecutive patients with definite IE according to the Duke criteria ${ }^{15} 16$ were referred to our echocardiographic laboratory. The Duke criteria were applied retrospectively to patients hospitalised before publication of the Duke criteria. All patients were examined by transthoracic echocardiography (TTE) and TOE. Of the 243 patients, 194 patients with a positive blood culture were prospectively enrolled. Patients without identified microorganisms $(n=49)$ were excluded. In 61 patients $(25.2 \%) S$ aureus was isolated, 15 patients $(6 \%)$ had Staphylococcus epidermidis IE, 85 patients (35\%) had streptococcal IE, 21 patients $(8.7 \%)$ had enterococcal IE, and 12 patients $(4.9 \%)$ had IE caused by uncommon microorganisms. The results of blood cultures were provided by the bacteriology laboratories and comprised identification of bacteria and antibiotic susceptibility testing. Patients were divided into two groups according to the microorganisms isolated: $S$ aureus IE group $(\mathrm{n}=61)$ and other pathogens IE group $(\mathrm{n}=133)$.

\section{Clinical parameters}

Age, sex, presence of co-morbidity (history of diabetes, cancer, haematological malignancy, cirrhosis, renal failure, dialysis, heart failure, or coronary artery disease), hypertension, valvar heart disease, valve prosthesis, cardiac surgery, and the presence of an intravascular device (venous catheter, pacemaker, or dialysis device) were analysed. A co-morbidity index taking into account the patient's age and history was calculated. ${ }^{1}{ }^{17}$

The following acute clinical events present on admission or occurring during hospitalisation were recorded: heart failure, neurological event, peripheral embolism, severe sepsis, multiple organ failure, and hospitalisation in the intensive care unit. The duration of symptoms before admission (interval between the presumed onset of symptoms and the date of admission for IE) and the portal of entry of the infection were investigated. Embolic events were diagnosed based on clinical signs and data derived from a non-invasive procedure (cerebral and thoraco-abdominal computed tomography recorded in $70 \%$ of patients). ${ }^{18}$ A major neurological event was defined as the development of an ischaemic stroke with hemiplegia, haemorrhagic stroke, cerebral abscess, features of encephalopathy, or coma. ${ }^{19}$ A minor neurological event was defined as a transient ischaemic attack or cerebral embolic accident with no serious clinical signs. ${ }^{19}$ Severe sepsis was defined as a systemic inflammatory syndrome secondary to an infectious process leading to organ dysfunction or signs of hypoperfusion or hypotension. ${ }^{20}$ Multiple organ failure was defined as dysfunction of at least two organs during hospitalisation for IE.

\section{Echocardiography}

Echocardiography was performed with a Hewlett Packard Sonos phased array (HP 1000, HP 2500 or HP 5500; Hewlett 
Table 1 Comparison of clinical setting of Staphylococcus aureus infective endocarditis (IE) versus IE caused by other pathogens

\begin{tabular}{llll}
\hline Variable & $\boldsymbol{S}$ aureus $(\mathbf{n}=61)$ & Other pathogens $(\mathbf{n}=133)$ & $\mathbf{p}$ Value \\
\hline Age (years) & ( & $60(14)$ & 0.20 \\
Men/women & $57(16)$ & $98(74 \%) / 35(26 \%)$ & 0.48 \\
Co-morbidity index $>4$ & $28(46 \%) / 19(31 \%)$ & $44(33 \%)$ & 0.086 \\
$\geqslant 1$ co-morbidities & $37(61 \%)$ & $58(44 \%)$ & 0.027 \\
$\geqslant 2$ co-morbidities & $22(36 \%)$ & $28(21 \%)$ & 0.026 \\
Hypertension & $21(34 \%)$ & $47(35 \%)$ & 0.9 \\
Diabetes & $12(20 \%)$ & $16(12 \%)$ & 0.16 \\
Cancer & $11(18 \%)$ & $30(23 \%)$ & 0.47 \\
Alcoholism & $12(20 \%)$ & $23(17 \%)$ & 0.68 \\
Cirrhosis & $3(5 \%)$ & $7(5.3 \%)$ & 1 \\
History of renal failure & $18(29 \%)$ & $10(7 \%)$ & $<0.001$ \\
Dialysis & $7(11 \%)$ & $2(1.5 \%)$ & 0.005 \\
History of heart failure & $6(10 \%)$ & $9(7 \%)$ & 0.45 \\
History of coronary disease & $5(8 \%)$ & $8(6 \%)$ & 0.57 \\
Intravascular device & $11(17 \%)$ & $14(11 \%)$ & 0.12 \\
\hline *Mean (SD). & & &
\end{tabular}

Packard, Andover, Massachusetts, USA) ultrasound machine with a $2.5 \mathrm{MHz}$ transthoracic transducer and a $5 \mathrm{MHz}$ transoesophageal transducer. TTE was systematically completed by TOE. All echocardiographic studies were performed by standard techniques and by experienced echocardiographers during the acute phase of IE without any complications. The presence, size, and location of valvar vegetation or perivalvar abscess were evaluated. Standard definitions were used for vegetations, abscesses, and other cardiac infective lesions. ${ }^{15} 2122$ All TOE recordings were reviewed by an experienced echocardiographer to measure in various planes the maximum length of vegetations ${ }^{18}$ and the maximum surface area of abscesses. ${ }^{23}$ The mobility of vegetations was graded on a scale of 1 to 4 with severe mobility corresponding to grade $4 .{ }^{24}$ Valvar regurgitation was quantified by Doppler echocardiography by standard method. ${ }^{25}$

\section{Follow up}

Follow up data included surgical treatment and death occurring during hospitalisation or follow up. Early surgery was defined as surgery performed during hospitalisation for management of IE. ${ }^{526}$ In-hospital mortality was defined as death occurring during the hospitalisation for IE. ${ }^{56}$ Overall mortality refers to death occurring during hospitalisation and follow up. Late mortality excluded death occurring during hospitalisation. All patients completed follow up with a mean follow up duration of 30 months.

\section{Statistical analysis}

Data were statistically analysed with SPSS 9.0 software (SPSS Inc, Chicago, Illinois, USA). Quantitative variables were expressed as the mean (SD). The two groups were compared by Student's $t$ test or $\chi^{2}$ test. The cumulative probability of survival was estimated by the Kaplan-Meier actuarial method at one month intervals and reported as mean (SE) estimated survival. The log rank test was used to determine any significant differences. To evaluate the impact of $S$ aureus IE on survival, multivariate models incorporating age, sex, co-morbidity index (taking the patient's age and history into account), usual prognostic factors (prosthetic valve, heart failure, major neurological events, renal failure, abscess, vegetation size), and early surgery were studied. A multivariate logistic regression model was used to determine in-hospital mortality and a Cox multivariate model for overall mortality. A probability value of $\mathrm{p}<0.05$ was considered significant.

\section{RESULTS}

\section{Baseline characteristics}

Of the 194 patients studied ( 140 men and 54 women, mean (SD) age 59 (15) years), 61 patients had $S$ aureus IE and 133 patients had IE caused by other microorganisms. Twenty four per cent of patients of our series were referred from another hospital. IE affected a native valve in $89 \%$ of patients and a valve prosthesis in $11 \%$ of patients (six mechanical prosthesis, 15 biological prosthesis). A vegetation was visualised in $98 \%$ of cases and a perivalvar abscess in $22 \%$. Early surgery was performed on $37 \%$ of patients (33\% of patients with $S$ aureus IE and $39 \%$ of patients in IE caused by other pathogens, $p=0.33$ ). The indications for early surgery were heart failure in 18 patients $(25 \%)$, embolic risk in $16(22 \%)$, uncontrolled infection in $15(21 \%)$, severe regurgitation in six $(8 \%)$, abscess in three $(4 \%)$, and multiple indications in 14 (19\%). In the 72 patients who underwent early surgery, 24 had mechanical valves, 22 had biological valves, 14 had mitral valve or tricuspid valve repair, six had pacemaker line extraction, four had multiple valve surgery, one had a homograft, and one had aortic valve vegetectomy.

Table 2 Comparison of patients' clinical characteristics during hospitalisation for $S$ aureus IE versus IE caused by other pathogens

\begin{tabular}{llll}
\hline Variable & $\begin{array}{l}\text { S aureus } \\
(\mathbf{n}=61)\end{array}$ & $\begin{array}{l}\text { Other } \\
\text { pathogens } \\
(\mathbf{n = 1 3 3 )}\end{array}$ & p Value \\
\hline Native valve disease & $55(90 \%)$ & $118(89 \%)$ & 0.76 \\
Prosthetic valve & $6(10 \%)$ & $15(11 \%)$ & 0.76 \\
Aortic IE & $22(36 \%)$ & $57(43 \%)$ & 0.37 \\
Mitral IE & $28(46 \%)$ & $46(35 \%)$ & 0.13 \\
Right sided IE & $11(18 \%)$ & $8(6 \%)$ & 0.009 \\
Multiple valve IE & $0(0 \%)$ & $24(18 \%)$ & $<0.001$ \\
Duration of symptoms (days) & $15(19)$ & $42(51)$ & $<0.001$ \\
Gl portal of entry & $0(0 \%)$ & $35(26 \%)$ & $<0.001$ \\
Cutaneous portal of entry & $29(47 \%)$ & $11(8 \%)$ & $<0.001$ \\
Heart failure & $19(31 \%)$ & $50(38 \%)$ & 0.38 \\
Severe sepsis & $24(39 \%)$ & $8(6 \%)$ & $<0.001$ \\
Stay in intensive care unit & $27(44 \%)$ & $14(10 \%)$ & $<0.001$ \\
Embolic event & $29(47 \%)$ & $56(42 \%)$ & 0.47 \\
Minor neurological event & $10(16 \%)$ & $26(19 \%)$ & 0.60 \\
Major neurological event & $11(18 \%)$ & $11(8 \%)$ & 0.04 \\
Multiple organ failure & $18(29 \%)$ & $14(10 \%)$ & 0.001 \\
Early surgery & $20(33 \%)$ & $52(39 \%)$ & 0.39 \\
In-hospital mortality & $21(34 \%)$ & $13(10 \%)$ & $<0.001$ \\
\hline *Mean (SD). & & & \\
Gl, gastrointestinal. & & & \\
\hline
\end{tabular}


Table 3 Comparison of echocardiographic characteristics of $S$ aureus IE versus IE caused by other pathogens

\begin{tabular}{llll}
\hline Variable & $\begin{array}{l}\boldsymbol{S} \text { aureus } \\
(\mathbf{n}=61)\end{array}$ & $\begin{array}{l}\text { Other } \\
\text { pathogens } \\
(\mathbf{n}=133)\end{array}$ & $\mathbf{p}$ Value \\
\hline Length of vegetation $(\mathrm{mm})^{*}$ & $14(8)$ & $12(7)$ & 0.21 \\
Severe mobile vegetation & $18(38 \%)$ & $38(30 \%)$ & 0.30 \\
Presence of abscess & $14(23 \%)$ & $23(14 \%)$ & 0.35 \\
Abscess area $\left(\mathrm{cm}^{2}\right)^{*}$ & $1.5(1.6)$ & $2.2(2.3)$ & 0.36 \\
Severe regurgitation & $17(30 \%)$ & $62(47 \%)$ & 0.014 \\
\hline *Mean (SD). & & & \\
\hline
\end{tabular}

The mean duration of antibiotic treatment before surgery was 10 (8) days in the $S$ aureus IE group and 15 (16) days in other pathogens group $(\mathrm{p}=0.30)$.

\section{Comparison of clinical characteristics}

Tables 1 and 2 show the results of univariate analysis comparing clinical setting and clinical characteristics during hospitalisation of $S$ aureus IE versus IE caused by other pathogens.

Mean age, sex ratio, prevalence of history of hypertension, history of heart failure, history of coronary disease, cancer, alcoholism, cirrhosis, frequency of prosthetic valve IE, aortic valve IE, acute heart failure, embolic event, minor neurological event, and of early surgery were comparable between the two groups (tables 1 and 2). Compared with IE caused by other pathogens, $S$ aureus IE was characterised by severe comorbidity $(\mathrm{p}=0.026)$, a shorter mean duration of symptoms before admission $(\mathrm{p}<0.001)$, a higher prevalence of history of renal failure $(p<0.001)$ and dialysis $(p=0.005)$, right sided IE $(p=0.009)$, a cutaneous portal of entry $(p<0.001)$, severe sepsis $(p<0.001)$, admission to the intensive care unit $(p<0.001)$, multiple organ failure $(\mathrm{p}=0.001)$, and major neurological events $(\mathrm{p}=0.04)$ (tables 1 and 2).

\section{Echocardiographic findings}

Table 3 compares echocardiographic characteristics. The presence and size of abscess, mean vegetation size, and
Table 4 Comparison of clinical complications among patients who died in hospital with $S$ aureus IE versus IE caused by other pathogens

\begin{tabular}{llll}
\hline & $\begin{array}{l}\text { S aureus } \\
\text { (n=21) }\end{array}$ & $\begin{array}{l}\text { Other } \\
\text { pathogens } \\
(\mathbf{n}=13)\end{array}$ & p Value \\
\hline Age (years) & $62(12)$ & $57(14)$ & 0.29 \\
Severe sepsis & $16(76 \%)$ & $3(23 \%)$ & 0.004 \\
Major neurological event & $7(33 \%)$ & $4(31 \%)$ & 1 \\
Renal failure & $9(43 \%)$ & $4(31 \%)$ & 0.7 \\
Heart failure & $11(52 \%)$ & $9(69 \%)$ & 0.33 \\
Multiple organ failure & $14(67 \%)$ & $6(46 \%)$ & 0.28 \\
\hline *Mean (SD). & & &
\end{tabular}

severe mobile vegetations were comparable in the two groups. Severe valvar regurgitation and multiple valve endocarditis were less frequent in the $S$ aureus IE group.

\section{Mortality}

In-hospital mortality was $17 \%$ in the total population. Compared with IE caused by other pathogens, the in-hospital mortality rate was higher in patients with $S$ aureus IE (34\% v $10 \%, \mathrm{p}<0.001)$. Table 4 reports the clinical complications of patients who died in hospital. Severe sepsis was more frequent in patients who died during the hospital phase of IE in the $S$ aureus IE group. Among the 61 patients with $S$ aureus IE, 21 died during the acute phase of IE. The causes of death in the $S$ aureus IE group were multiorgan failure in 12 patients, neurological event in two, sudden death in three, heart failure in one, operative death in two, and tamponade in one. The causes of death among the 13 patients who died in the other pathogens group during the acute phase of IE were multiorgan failure in five patients, neurological event in two, sudden death in three, and operative death in three. The mean duration of antibiotic treatment before death was 22 (19) days in the $S$ aureus IE group versus 22 (18) days $(\mathrm{p}=0.95)$.

The overall 36 month mortality rate was 35\%. By multivariate analyses $S$ aureus infection was identified as a powerful predictive factor for in-hospital mortality and for overall mortality (tables 5 and 6). The 36 month actuarial

Table 5 Impact of $S$ aureus infection on in-hospital mortality: results of logistic regression analysis models

\begin{tabular}{llll}
\hline Model & OR & $95 \%$ Cl & p Value \\
\hline Age and sex adjusted models & & & \\
Age & 1 & 0.98 to 1 & 0.47 \\
Sex & 0.5 & 0.2 to 1.3 & 0.20 \\
Staphylococcus IE & 5.2 & 2.3 to 11.5 & $<0.001$ \\
Sex, C index, and usual prognosis variables adjusted models & 0.4 & & \\
Sex & 1.2 & 0.13 to 1.2 & 0.13 \\
C Index & 3.1 & 0.98 to 1.5 & 0.06 \\
Prosthetic valve & 9.1 & 0.53 to 18.8 & 0.20 \\
Major neurological event & 4.9 & 2.6 to 31 & 0.0004 \\
Heart failure & 1.2 & 1.7 to 13.7 & 0.0021 \\
Abscess & 1.03 & 0.35 to 4.1 & 0.75 \\
Vegetation size & 6.4 & 0.97 to 1.1 & 0.20 \\
Staphylococcus IE & 2.4 to 16.6 & 0.0001 \\
Age, sex, usual prognosis factors, and early surgery & adjusted models & & \\
Age & 1 & 0.96 to 1.04 & 0.87 \\
Sex & 0.4 & 0.11 to 1.44 & 0.16 \\
Early surgery & 0.51 & 0.16 to 1.56 & 0.24 \\
Prosthetic valve & 3.86 & 0.59 to 25 & 0.15 \\
Renal failure & 6.3 & 1.9 to 20.4 & 0.0022 \\
Abscess & 1.6 & 0.45 to 5.66 & 0.46 \\
Vegetation size & 1.04 & 0.97 to 1.12 & 0.17 \\
Major neurological event & 10.4 & 2.7 to 39 & 0.0005 \\
Heart failure & 5.3 & 1.8 to 15 & 0.0023 \\
Staphylococcus IE & 4.7 & 1.7 to 13.3 & 0.0029 \\
\hline C index, co-morbidity (including age and renal failure) ; Cl, confidence interval; OR, odds ratio. & \\
\hline
\end{tabular}




\begin{tabular}{|c|c|c|c|}
\hline Model & Hazard ratio for death & $95 \% \mathrm{Cl}$ & p Value \\
\hline \multicolumn{4}{|l|}{ Age and sex adjusted models } \\
\hline Age & 1.02 & 1 to 1.03 & 0.022 \\
\hline Female sex & 0.7 & 0.45 to 1.3 & 0.40 \\
\hline Staphylococcus IE & 2.2 & 1.3 to 3.6 & 0.001 \\
\hline \multicolumn{4}{|c|}{ Sex, $C$ index, and usual prognosis variables adjusted models } \\
\hline Sex & 0.56 & 0.32 to 0.97 & 0.04 \\
\hline$C$ index & 1.3 & 1.17 to 1.44 & $<0.0001$ \\
\hline Prosthetic valve & 2.5 & 1.17 to 5.3 & 0.017 \\
\hline Major neurological event & 3.2 & 1.7 to 6.2 & 0.0003 \\
\hline Heart failure & 1.8 & 1.12 to 3.04 & 0.015 \\
\hline Abscess & 1.03 & 0.54 to 1.9 & 0.92 \\
\hline Vegetation size & 0.99 & 0.96 to 1.03 & 0.99 \\
\hline Staphylococcus IE & 1.9 & 1.2 to 3.2 & 0.0054 \\
\hline \multicolumn{4}{|c|}{ Age, sex, early surgery, and usual prognosis variables adjusted models } \\
\hline Age & 1 & 0.99 to 1.02 & 0.31 \\
\hline Sex & 0.68 & 0.39 to 1.20 & 0.19 \\
\hline Surgery & 0.53 & 0.29 to 0.95 & 0.035 \\
\hline Prosthetic valve & 2.5 & 1.22 to 5.43 & 0.012 \\
\hline Renal failure & 2.1 & 1.18 to 4.04 & 0.012 \\
\hline Abscess & 1.05 & 0.54 to 2.02 & 0.87 \\
\hline Vegetation size & 1.01 & 0.97 to 1.04 & 0.48 \\
\hline Major neurological event & 3.37 & 1.08 to 6.3 & 0.0001 \\
\hline Heart failure & 2.26 & 1.36 to 3.77 & 0.0016 \\
\hline Staphylococcus IE & 1.8 & 3.1 & 0.017 \\
\hline
\end{tabular}

overall survival rate was significantly lower in the $S$ aureus IE group than in the group with IE caused by other pathogens $(47 \%$ v $68 \%, \mathrm{p}=0.002)$ ) fig 1$)$.

Thirty four of the 160 survivors after hospitalisation died after discharge during the 36 month follow up. The causes of late death were heart failure in seven patients, neurological event in four, cancers in seven, sudden death in two, myocardial infarction in one, operative death in one patient who underwent cardiac surgery after discharge at four months, and unknown in 12. The 36 month late survival rate after discharge was similar in the two groups $(72 \% \mathrm{v}$ $75 \%, \mathrm{p}=0.95$; fig 2 ).

\section{DISCUSSION}

Our study of 194 patients with definite IE according to the Duke criteria $^{15}{ }^{16}$ shows that $S$ aureus IE compared with IE caused by other pathogens is characterised by a shorter duration of symptoms before diagnosis and by a higher prevalence of co-morbidity, history of renal failure, right sided IE, cutaneous portal of entry, severe sepsis, major

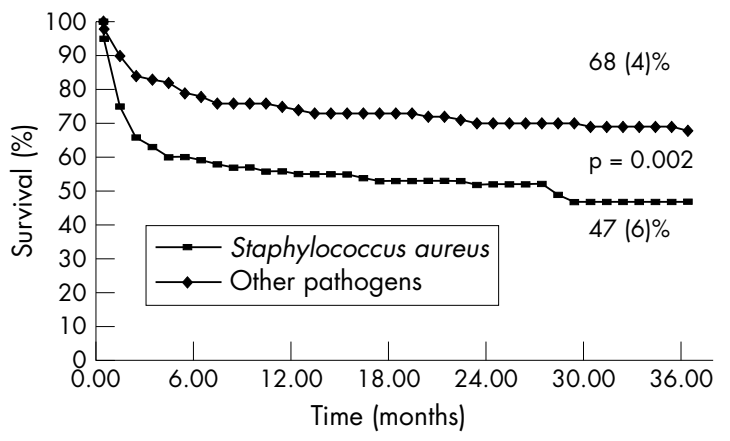

Other

$\begin{array}{llllllll}\text { pathogens IE } & 133 & 93 & 78 & 71 & 65 & 59 & 54\end{array}$ $\begin{array}{llllllll}S \text { aureus IE } & 61 & 33 & 30 & 25 & 24 & 19 & 17\end{array}$

Figure 1 Kaplan-Meier overall survival curves of patients with Staphylococcus aureus infective endocarditis (IE) and IE caused by other pathogens. The survival of patients with $S$ aureus IE is lower $(47 \%)$ than that of patients with IE caused by other pathogens (68\%, $p=0.002$ ). neurological events, and multiple organ failure. $S$ aureus IE is more severe in terms of morbidity and mortality. To our knowledge, clinical and morphological characteristics have not been compared between $S$ aureus IE and IE caused by other pathogens in terms of the Duke criteria.

$S$ aureus IE has been reported with increasing frequency during the past decades ${ }^{36}{ }^{13}$ and has emerged as a dominant cause of IE. ${ }^{627}$ In our study $S$ aureus was responsible for $25 \%$ of all cases of IE. $S$ aureus IE usually occurs in a debilitated clinical setting: chronic renal failure, haemodialysis, diabetes, alcoholism, cancer, haematological malignancy, immunodepression, and drug addiction. ${ }^{62829}$ In our study, severe comorbidity was associated with $S$ aureus IE. The association between haemodialysis, renal failure, and $S$ aureus IE was confirmed in our study. This susceptibility may be caused in part by an underlying disease and its treatment (immunosuppression, intravenous catheter). $S$ aureus is a bacterium that easily adheres to inert structures. Intravascular device associated $S$ aureus IE has recently been recognised as an emerging problem by other investigators. ${ }^{13}{ }^{30}$ In our series, the presumed source of infection was an intravascular device in

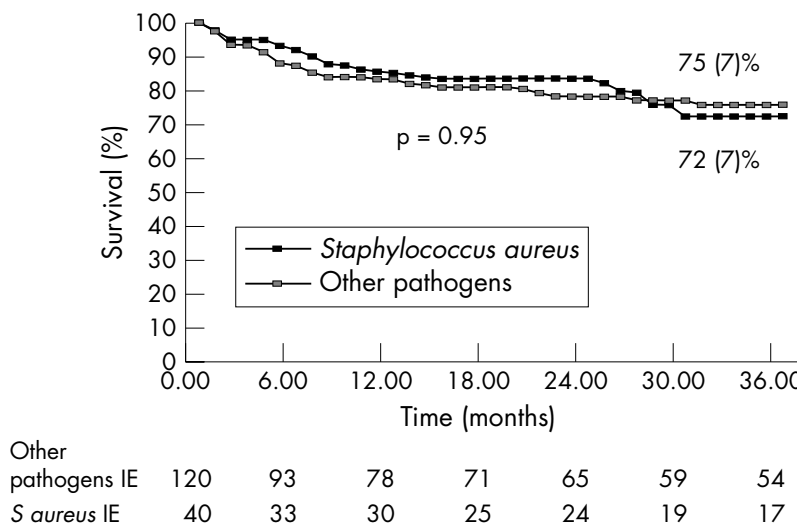

Figure 2 Kaplan-Meier late survival curves of patients with $S$ aureus IE and IE caused by other pathogens. Late survival was similar in both groups (S aureus IE, 72\%; other pathogens, 75\%; $p=0.95$ ). 
$17 \%$ of patients with $S$ aureus IE. ${ }^{29}$ Right sided IE was more frequent in the $S$ aureus IE group. ${ }^{13}$ Not surprisingly, the cutaneous portal of entry was identified as a major source of infection in the $S$ aureus IE group in our study. Only three patients in our study had a history of injecting drug use.

$S$ aureus is a malignant disease known to be responsible for severe sepsis. ${ }^{31}{ }^{32}$ Accordingly, admission to the intensive care unit, development of severe sepsis, and multiple organ failure were significantly more frequent in the $S$ aureus IE group in our study. This virulence has been ascribed to a variety of complex factors, which include its capsule and cell wall, the production of extracellular enzymes and toxins that promote tissue invasion, its capacity to persist intracellularly in phagocytes, and its potential to acquire resistance to antimicrobials. Clinical signs of $S$ aureus IE appear and evolve rapidly, leading to hospital admission ${ }^{3914}$ as illustrated by the shorter mean duration of symptoms in the $S$ aureus IE group in our study. Neurological complications are sometimes the first presenting signs of IE. Symptoms may range from simple confusion to unexplained coma. ${ }^{19}{ }^{33}$ Previous series have noted a high incidence of neurological events in $S$ aureus IE. ${ }^{19} 3435$ Accordingly, a high frequency of $18 \%$ major neurological events in the $S$ aureus IE group compared with $8 \%$ in IE caused by other pathogens was observed in our series. Only $11 \%$ of embolic events occurred after initiation of antibiotics. Because not all patients underwent cerebral and thoraco-abdominal computed tomography, the true incidence of embolic events in the current study may have been underestimated. The frequency of heart failure, one of the main complications of IE, was comparable in the two groups. Surgery was performed according to established guidelines, predominantly in the presence of a complication such as recurrent embolism, heart failure, or evidence of perivalvar extension. ${ }^{36}{ }^{37}$ Because of the virulence of $S$ aureus and the severity of the clinical features, some authors recommend aggressive management with very broad indications for early surgery performed in $33 \%$ of cases in the current series. ${ }^{3} 38$ However, surgery in the $S$ aureus group is sometimes not performed because of a prohibitive operative risk related to the debilitated clinical setting associated with extremely severe clinical features and multiorgan failure ( six patients in our series). In our study, as in other series reported in the literature, ${ }^{139-41}$ early surgery defined as surgery performed during hospitalisation for management of $\mathrm{IE}^{526}$ was also frequent in the group with IE caused by other pathogens. The benefit of early surgery in patients with $S$ aureus IE was not addressed in the current study, which has the disadvantages of observational studies of consecutive patients where the decision to operate or not was not randomised but based on the clinical judgement of the physician or surgical team. Thus, further studies are needed to evaluate whether earlier surgical intervention for selected patients will improve the outcome of $S$ aureus IE. $^{37}$

$S$ aureus IE is associated with high morbidity and mortality. $S$ aureus IE compared with IE caused by other pathogens occurs in a more debilitated clinical setting. The prognosis of $S$ aureus IE is therefore very serious, with a more severe prognosis than with IE caused by other pathogens and with a high in-hospital mortality of $34 \%$ in our series, which ranges between $30-46 \%$ according to various authors, ${ }^{1-3} 3142$ even reaching $71 \%$ in a study published in $1986 .{ }^{9}$ The present study showed that in IE, independent of age, sex, co-morbidity index or usual prognostic factors, $S$ aureus infection causes an excess risk of in-hospital mortality and of overall mortality. Because $S$ aureus right sided IE is a different disease, we performed a separate prognostic multivariate analysis excluding $S$ aureus right sided IE. We obtained similar results to the analysis including all patients. Patients with $S$ aureus prosthetic IE are a very high risk subgroup. In the current study we had only six patients with a prosthetic valve in the $S$ aureus IE group. Therefore, we could not specifically analyse $S$ aureus prosthetic IE and compare it with non-S aureus IE. We cannot exclude the possibility that our patients may constitute a selected cohort from a referral centre with more severe illness than the average population with IE. Thus, the differences in mortality and morbidity may to some extent be a result of referral bias.

The excess mortality associated with $S$ aureus IE in the current study, essentially related to the severity of sepsis and the particularly high risk clinical setting, mainly occurs during the hospital phase as indicated by actuarial survival curves, which tend to become parallel in the two groups after discharge from hospital (fig 1). Accordingly, $S$ aureus infection was not a predictive factor of late mortality. Rapid management is therefore essential with a need for early surgery in selected patients. ${ }^{36} 38$

\section{Authors' affiliations}

G Nadji, J P Rémadi, F Coviaux, A Ali Mirode, A Brahim, C Tribouilloy, Department of Cardiovascular Disease, CHU Amiens, Amiens, France M Enriquez-Sarano, Division of Cardiovascular Diseases and Internal Medicine, Mayo Clinic and Mayo Foundation, Rochester, Minnesota, USA

\section{REFERENCES}

1 Hoen B, Alla F, Selton-Suty C, et al. Changing profile of infective endocarditis: results of a 1-year survey in France. JAMA 2002;288:75-81.

2 Van der Meer JT, Thompson J, Valkenburg HA, et al. Epidemiology of bacterial endocarditis in the Netherlands. Arch Intern Med 1992:152:1869-73.

3 Sanabria TJ, Alpert JS, Goldberg R, et al. Increasing frequency of staphylococcal infective endocarditis: experience at a university hospital, 1981 through 1988. Arch Intern Med 1990;150:1305-9.

4 Hogevik H, Olaison L, Andersson R, et al. Epidemiologic aspects of infective endocarditis in an urban population: a 5 -year prospective study. Medicine (Baltimore) 1995;74:324-39

5 Steckelberg JM, Melton $\sqcup$, Ilstrup DM, et al. Influence of referral bias on the apparent clinical spectrum of infective endocarditis. Am J Med 1990;88:582-8.

6 Cabell CH, Jollis JG, Peterson GE, et al. Changing patient characteristics and the effect on mortality in endocarditis. Arch Intern Med 2002;162:90-4.

7 Ako J, Ikari $Y$, Hatori $M$, et al. Changing spectrum of infective endocarditis: review of 194 episodes over 20 years. Circ J 2003;67:3-7.

8 Mouly S, Ruimy R, Launay $O$, et al. The changing clinical aspects of infective endocarditis: descriptive review of 90 episodes in a French teaching hospital and risk factors for death. J Infect 2002;45:246-56.

9 Espersen F, Frimodt-Moller N. Staphylococcus aureus endocarditis: a review of 119 cases. Arch Intern Med 1986;146:1118-21.

10 Thompson RL. Staphylococcal infective endocarditis. Mayo Clin Proc 1982:57:106-14.

11 Watanakunakorn C. Staphylococcus aureus endocarditis at a community teaching hospital, 1980 to 1991: an analysis of 106 cases. Arch Intern Med 1994;154:2330-5.

12 Chambers HF, Korzeniowski OM, Sande MA. Staphylococcus aureus endocarditis: clinical manifestations in addicts and nonaddicts. Medicine (Baltimore) 1983;62:170-7.

13 Fowler VG, Sanders LL, Kong LK, et al. Infective endocarditis due to Staphylococcus aureus: 59 prospectively identified cases with follow-up. Clin Infect Dis 1999;28:106-14.

14 Roder BL, Wandall DA, Frimodt-Moller N, et al. Clinical features of Staphylococcus aureus endocarditis: a 10-year experience in Denmark. Arch Intern Med 1999;159:462-9.

15 Durack DT, Lukes AS, Bright DK. New criteria for diagnosis of infective endocarditis: utilization of specific echocardiographic findings. Am J Med 1994;96:200-9.

16 Habib G, Derumeaux G, Avierinos JF, et al. Value and limitations of the Duke criteria for the diagnosis of infective endocarditis. J Am Coll Cardiol 1999;33:2023-9.

17 Charlson ME, Pompei P, Ales KL, et al. A new method of classifying prognostic comorbidity in longitudinal studies: development and validation. J Chronic Dis 1987;40:373-83.

18 Di Salvo G, Habib G, Pergola V, et al. Echocardiography predicts embolic events in infective endocarditis. $J$ Am Coll Cardiol 2001;37:1069-76.

19 Roder BL, Wandall DA, Espersen F, et al. Neurologic manifestations in Staphylococcus aureus endocarditis: a review of 260 bacteremic cases in nondrug addicts. Am J Med 1997;102:379-86.

20 Bone RC, Balk RA, Cerra FB, et al. Definitions for sepsis and organ failure and guidelines for the use of innovative therapies in sepsis. Chest 1992; 101:1644-55. 
21 Shapiro SM, Young E, De Guzman S, et al. Transesophageal echocardiography in diagnosis of infective endocarditis. Chest 1994; 105:377-82.

22 Daniel WG, Mugge A, Martin RP, et al. Improvement in the diagnosis of abscesses associated with endocarditis by transesophageal echocardiography. N Engl J Med 1991;324:795-800.

23 Tribouilloy C, Ruiz V, Roudaut R, et al. [Outcome of cardiac valve ring abscesses after medical treatment: attempt to identify criteria of favorable prognosis]. Presse Med 1996;28:1276-80.

24 Sanfilippo A, Picard M, Newell J. Echocardiographic assessment of patients with infectious endocarditis: prediction of risk for complications. J Am Coll Cardiol 1991:18:1991-9.

25 Tribouilloy C, Enriquez-Sarano M, Peltier M. Quantification des valvulopathies acquises par échodoppler. In: Acar J, Acar C, eds. Cardiopathies valvulaires acquises. Paris: Flammarion Médecines-Sciences, 2000:82-114.

26 Aranki SF, Adams DH, Rizzo RJ, et al. Determinants of early mortality and late survival in mitral valve endocarditis. Circulation 1995;92:143-9.

27 Petti CA, Fowler VG. Staphylococcus aureus bacteremia and endocarditis. Infect Dis Clin North Am 2002;16:413-35.

28 Robinson DL, Fowler VG, Sexton DJ, et al. Bacterial endocarditis in hemodialysis patients. Am J Kidney Dis 1997;30:521-4.

29 Marr KA, Kong L, Fowler VG, et al. Incidence and outcome of Staphylococcus aureus bacteremia in hemodialysis patients. Kidney Int 1998:54:1684-9.

30 Govello JP, Asfar P, Brenet O, et al. Nosocomial endocarditis in the intensive care unit: an analysis of 22 cases. Crit Care Med 2000;28:377-82.

31 Wolff $M$, Witchitz S, Chastang $C$, et al. Prosthetic valve endocarditis in the ICU: prognostic factors of overall survival in a series of 122 cases and consequences for treatment decision. Chest 1995;108:688-94.
32 Mansur AJ Grinberg M, da Luz PL, et al. The complications of infective endocarditis: a reappraisal in the 1980s. Arch Intern Med endocarditis: a reapp

33 Kanter MC, Hart RG. Neurologic complications of infective endocarditis. Neurology 1991:41:1015-20.

34 Heiro M, Nikoskelainen J, Engblom E, et al. Neurologic manifestations of infective endocarditis: a 17-year experience in a teaching hospital in Finland. Arch Intern Med 2000;160:2781-7.

35 Hart RG, Foster JW, Luther MF, et al. Stroke in infective endocarditis. Stroke 1990;21:695-700.

36 Bayer A, Bolger A, Taubert K, et al. Diagnosis and managment of infective endocarditis and its complications. Circulation 1998;98:2936-48.

37 Chu VH, Cabell CH, Benjamin DK Jr, et al. Early predictors of in-hospital death in infective endocarditis. Circulation 2004;109:1745-9.

38 Roder B, Wandall D, Espersen F, et al. A study of 47 bacteremic Staphylococcus aureus endocarditis cases: 23 with native valves treated surgically and 24 with prosthetic valves. Scand Cardiovasc J 1997;31:305-9.

39 Kupferwasser I, Darrius H, Müller A, et al. Clinical and morphological characteristics in Streptococcus bovis endocarditis: a comparison with other causative microorganisms in 177 cases. Heart 1998;80:276-80.

40 lung B, Rousseau-Paziaud J, Cormier B, et al. Contemporary results of mitral valve repair for infective endocarditis. J Am Coll Cardiol 2004:43:386-92

41 Senni M, Merlo M, Sangiorgi G, et al. Mitral valve repair and transesophageal echocardiographic findings in a high-risk of patient with active, acute infective endocarditis. J Heart Valve Dis 2001;10:72-7.

42 Watanakunakorn C, Burkert T. Infective endocarditis at a large community teaching hospital, 1980-1990: a review of 210 episodes. Medicine 1993;72:90-102

\section{IMAGES IN CARDIOLOGY}

\section{Spontaneous stent-edge spasm in a patient with myocardial infarction}

\begin{abstract}
A 57 year old Japanese man who had no history of vasospastic angina was admitted because of acute myocardial infarction complicated by ventricular fibrillation. He was resuscitated by cardioversion. Coronary angiography revealed a $90 \%$ stenosis in the proximal portion of the left anterior descending artery (LAD). A coronary stent (Zeta stent $3.5-28 \mathrm{~mm}$ ) was deployed in the proximal LAD lesion. Although he had been asymptomatic, follow up angiography was performed four months later. In the first angiogram of the LAD, luminal narrowing at the stent distal edge was noted (panel A: white arrows denote the stent-edge spasm site). We considered the following two possibilities: stent-edge restenosis had occurred or there was spontaneous stent-edge spasm. Ergonovine was injected into the LAD in incremental doses of $10 \mu \mathrm{g}$ (panel B) and $20 \mu \mathrm{g}$ (panel C) over four minutes. After the injection of ergonovine, luminal narrowing at the distal edge of the stent increased (panel B) and severe narrowing with filling delay was observed (panel C). The spasm resolved with intracoronary administration of $3 \mathrm{mg}$ of isosorbide dinitrate and the luminal narrowing at the stent distal edge disappeared (panel D). After follow up angiography, treatment with a calcium channel antagonist was started. Although spontaneous stent-edge spasm is rare, we should not neglect this phenomenon.
\end{abstract}

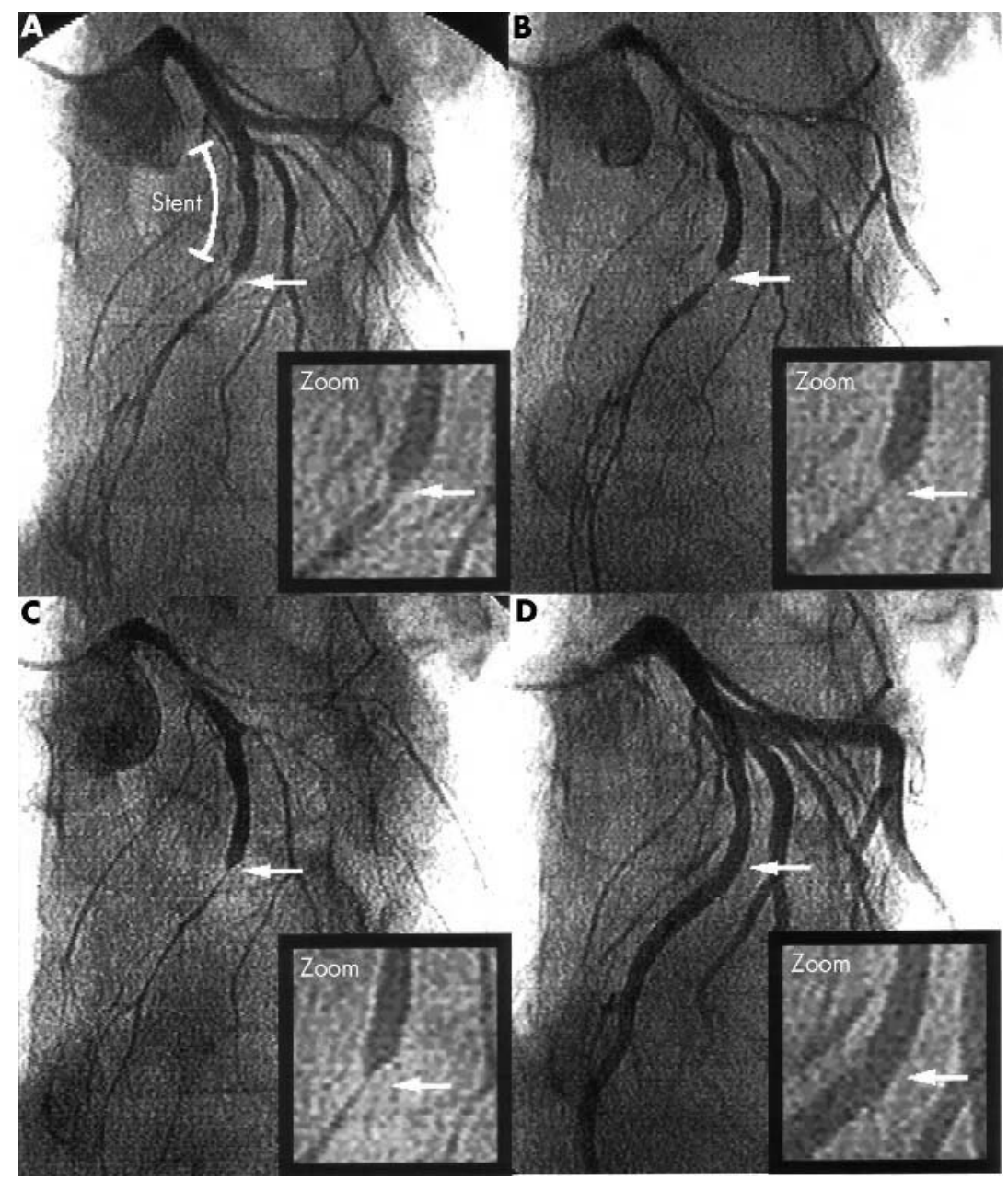

B Kaku

H Kanaya

Y Horita

3kaku@nyc.odn.ne.jp 